\title{
Modelling of a Hydro Power Station in an Island Operation
}

\author{
Arndís Magnúsdóttir ${ }^{1}$ Dietmar Winkler ${ }^{2}$ \\ ${ }^{1}$ Verkís hf, Iceland, armeverkis.is \\ ${ }^{2}$ University College of Southeast Norway, dietmar.winkler@usn. no
}

\begin{abstract}
There is a strong focus on new renewable energy sources, such as, solar power, wind energy and biomass, in the context of reducing carbon emissions. Because of its maturity, hydropower is often overlooked. However, there is an era of hydro oriented research in improving many aspects of this well established technology.

Representing a physical system of a hydropower plant by mathematical models can serve as a powerful tool for analysing and predicting the system performance during disturbances. Furthermore it can create opportunities in investigating more advanced control method.

A simulation model of a reference hydropower station located in northwest of Iceland was implemented using the modelling language Modelica ${ }^{\circledR}$. The main simulation scenarios of interest were: $20 \%$ load rejection, worst-case scenario of full shut-down and pressure rise in the pressure shaft due to the water hammer effect. This paper will show that the different simulation scenarios were successfully carried out based on the given the data available of the Fossárvirkjun power plant. The load rejection simulation gave expected results and was verified against a reference results from manufacturer.

Keywords: Hydropower in Iceland, modelling, simulation, island operation, Modelica, Dymola, Electric Power Library, Hydro Power Library, water hammer effect
\end{abstract}

\section{Introduction}

The process of using the energy of moving water to create electricity is a long-standing, well-proven and reliable technology. Unlike other renewable energy sources, hydropower is not a recent development but has been around for several hundredths of years. As of today the availability of hydropower has been associated with kick-starting economic growth (International Hydropower Association 2016).

There is a strong focus on renewable energy sources in the context of the desired global reduction in carbon emissions. Technologies such as solar power, wind energy and biomass are in focus while hydropower is often overlooked. Hydropower has many advantage when it comes to the effect of climate change as it is renewable, efficient and reliable source of energy that does not directly emit greenhouse gasses. Because of its maturity, hydropower is often associated with conservative and perhaps stagnant technology development. However, there is an area of hydro-oriented research in improving many aspects of this well established technology, taking full advantage of progress in science and engineering (Munoz-Hernandez, Mansoor, and Jones 2013).

Around $70 \%$ of Iceland's electricity is produced from hydroelectric power and is the world's largest electricity producer per capita. In cooperation with Icelandic oldest and leading consulting engineers in energy production, Verkís hf, a complete dynamic hydropower model was implemented based on a reference power station, Fossárvirkjun, located in the northwest region of Iceland. The objective of developing such model is to study the dynamic characteristics of the plant, such as load rejection and to explore worst-case scenario of a full shut-down of the plant. Furthermore, the effect of water hammer, following pressure rise in the pressure shaft will be of outermost interest since Fossárvirkjun's water-way has no surge tank installed. Water inertia is the main aspect that influences the water hammer waves in the pressure shaft.

To build such model and to simulate these different scenarios the object-oriented modelling language, Modelica ${ }^{\circledR}$, is used to model the complex, physical power plant. The commercial modelling and simulation environment Dymola (Dassault Systèmes 2016), a product of Dassault Systémes, was used. In addition, two separate libraries, the Hydro Power Library(HPL) and the Electric Power Library(EPL) (Modelon AB 2016) will be coupled together in order to represent the complete hydro power system.

\subsection{Fossárvirkjun}

In the year 1937, a hydropower station was built to serve Ísafjörður, located in the northwest region of Iceland in Skutulsfjörður, in the Westfjords. At that time, it was the only electric power source for the Ísafjörður area. Since then there has been no refurbishment until now. The Westfjord Power Company has refurbished the existing power station with a new turbine/generator and electrical equipment. A new pressure shaft and a new powerhouse were constructed about $800 \mathrm{~m}$ from the existing one and the new power station is named Fossárvirkjun. The existing $600 \mathrm{~kW}$ Pelton machine was replaced by a new $1200 \mathrm{~kW}$ Pelton turbine. The new refurbished power plant serves Súðavík in an island operation (Refurbishment of the Fossár hydro Power Plant 2015). Figure 1 shows the new power house of Fossárvirkjun.

The reference system used for the modelling part is the 


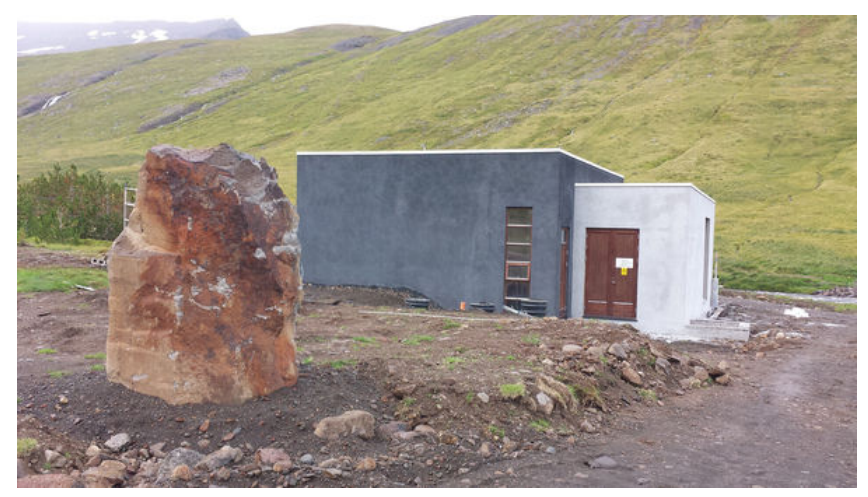

Figure 1. Power house of Fossárvirkjun (Refurbishment of the Fossár hydro Power Plant 2015)

new refurbished Fossárvirkjun that started operation in autumn of 2016.

The reservoir is Fossavatn, a fresh water which is mostly fed by direct runoffs and springs. The intake is at 343 m.a.s.l. and the rated discharge is at $0.45 \mathrm{~m}^{3} / \mathrm{s}$. The pressure shaft is around 1900 metres long consisting of a DN500 GRP pipe with no surge facility. The turbine is a two-nozzle horizontal Pelton turbine. Since Fossárvirkjun will be running in island operation two simulation scenarios are of interest.

As has been mentioned, there is no surge tank to absorb a sudden rise of pressure in the pressure shaft. Therefore, the pressure at the bottom of the pressure shaft, has to be closely monitored. Table 1 summarises the general information data of the system.

Table 1. General data table of Fossárvirkjun

\begin{tabular}{lrl}
\hline Properties & Values & unit \\
\hline Pressure shaft & & \\
Length & 1900 & {$[\mathrm{~m}]$} \\
Inner Diameter & 0.50 & {$[\mathrm{~m}]$} \\
Nominal pressure in pressure shaft & 32 & {$[\mathrm{bar}]$} \\
Maximum over pressure & 15 & {$[\%]$} \\
\hline Pelton Turbine & & \\
Number of Nozzles & 2 & \\
Rated Discharge & 0.45 & {$\left[\mathrm{~m}^{3} / \mathrm{s}\right]$} \\
Rated Net Head & 308 & {$[\mathrm{~m}]$} \\
Turbine Efficiency & 91 & {$[\%]$} \\
\hline Synchronous Generator & & \\
Power & 1404 & {$[\mathrm{kVA}]$} \\
Max mechanical power & 1325 & {$[\mathrm{~kW}]$} \\
Nominal Voltage & 400 & {$[\mathrm{~V}]$} \\
Nominal Current & 2026.5 & {$[\mathrm{~A}]$} \\
\hline
\end{tabular}

A rough sketch of the real water-way of Fossárvirkjun is depicted in Figure 2. The intake is at 343 m.a.s.l. and the connection to the turbine at 38 m.a.s.l. The length of the water-way roughly $1900 \mathrm{~m}$, keeping in mind that the actual length of the pipe segments is longer.

The turbine runner is fixed on the generator's shaft. The generator is a standard $400 \mathrm{~V}$ AC synchronous machine with a brush-less excitation system. The governor is a PID controller.

\section{Modelling}

The Modelica simulation environment used in this project was Dymola which is commercial tool for modelling and simulation of complex systems. It is a product of Dassault Systémes. Dymola allows the user to create a graphical representation of a physical system and has different solvers to choose from. Modelica is multidomain modelling language which means that different libraries produced by sometimes several developers can be coupled together if needed. Taking the advantage of this multidomain modelling, two types of libraries were used to build the dynamic model of Fossárvirkjun; Hydro Power Library and Electric Power Library.

The complete power system of Fossárvirkjun can be seen in Figure 3. The model entails different source components that are connected together.

The reason why the EPL has to be coupled with the HPL is that even though the HPL contains an electrical system, it does not give information about active or reactive power, that is, it is only calculating active power quantities.

\subsection{The Water-Way}

The water-way was modelled using components from the HPL that calculate the media state vectors $(f(p, T))$ and media flow of the water.

An important assumption made in the modelling is that the states are uniformly distributed. It is assumed in the upcoming modelling that the water head is constant, that is, assuming that the water source is an infinite. Figure 4 shows the water-way sub-component.

Mass, energy and momentum balance equations are discretised with the finite volume method using an upwind discretisation scheme. State variables are pressure, temperature and mass-flow for each pipe segment. Each pipe segment is split up by a combination of closed volume models and mass flow models. For each pipe segment the two models contain the following

\section{Closed Volume Models}

- Conservation laws: Energy Balance and Mass Balance

- State variables: Pressure $(p)$ and temperature $(T)$

- Inflow and outflow: Flow of mass and enthalpy

\section{Mass Flow Models}

- Conservation Laws: Momentum Balance

- State variables: Mass flow $\dot{m}$

- Outflow: $\dot{m}_{\text {out }}$ 


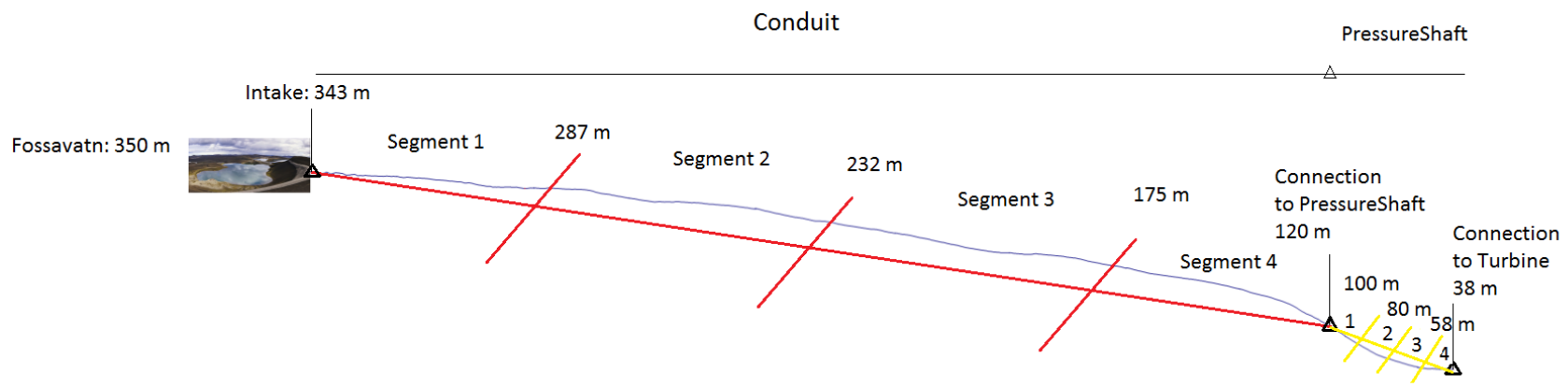

Figure 2. From the real water-way of Fossárvirkjun to modelled water-way in Modelica, split by segments.

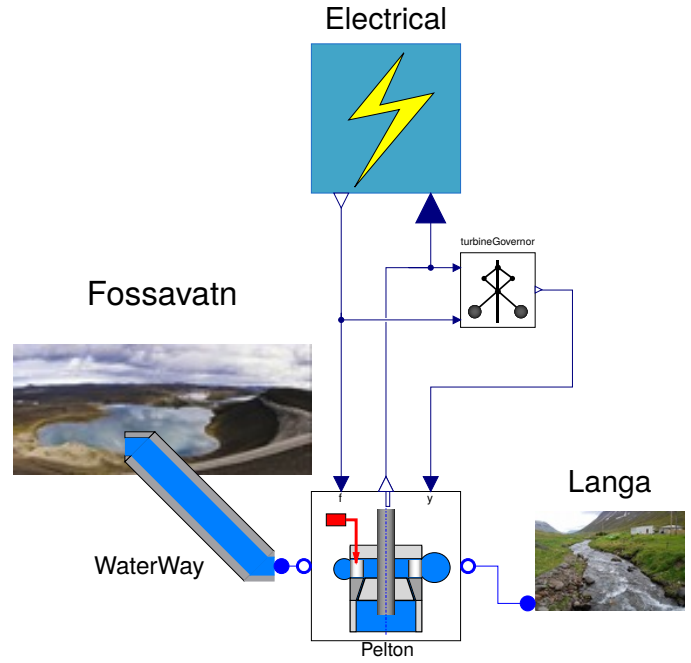

Figure 3. Complete model of Fossárvirkjun in Dymola

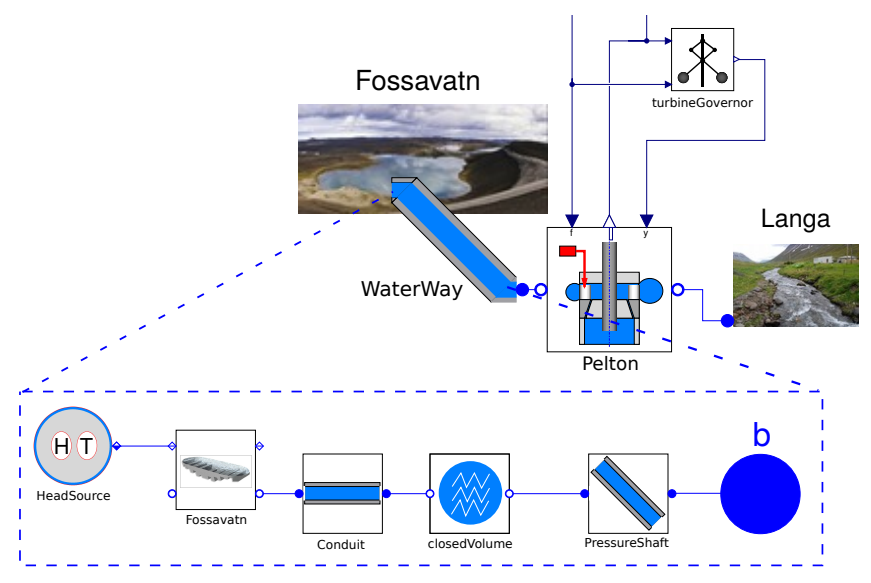

Figure 4. Submodel: Water-way

\subsubsection{Finite Volume Method}

For one phase flow models, the partial differential equations of mass, energy and momentum are discretised and solved with the finite volume method where they are integrated and approximated by ordinary differential equa- tions. The Finite Volume Method is considered to be particularly good at maintaining the conserved quantities (Elmqvist, Tummescheit, and Otter 2003).

The conduit in Fossársvirkjun is a uniform pipe, but modelled with two separate pipes, the conduit and the pressure shaft. This was done in order to be able to analyse the pressure shaft in more details because of the special interest in the pressure rise.

The water-way sub-component consists of a head source, reservoir (Fossavatn), conduit, closed volume and pressure shaft:

Head Source Infinite source of volume with prescribed details about water height and temperature.

Reservoir/Fossavatn Detailed reservoir built with $\mathrm{n}$ segments. Using massflow models which calculates using momentum balance for fluid segments that is between two open channel segments/reservoir.

Conduit/Pressure shaft Model of discretised pipe with massflow models at inlet and outlet. Using the upwind scheme of finite volume method to discretise the balance equations; Mass, Momentum and Energy. Pressure, temperature and mass-flow are the state variables. This pipe is made up of $n$ segments.

Closed Volume Used to connect the conduit and pressure shaft together. As the name implies, it is a closed volume with state variables as pressure and temperature.

In relation to the model of the water-way in Figure 4 where different sub-components come together to create the water-way,

The earlier Figure 2 shows also how the different subcomponents were used in order to build the model of the head-race water-way. The conduit model (red line in the figure) is divided into four segments. It begins at the intake and ends at the junction with the pressure shaft. The pressure shaft then starts descending at this junction and continues all the way to the turbine inlet. The real waterway of Fossárvirkun is the blue line in the background. 
As Figure 2 shows, there is some loss in detail in the water-way while modelling. From one junction to another, the conduit pipe is modelled as a straight line. In theory, you could have numerous of segments throughout the conduit and subsequently minimising the loss of detail but with the cost of the simulation being computational demanding.

As mentioned before, the conduit is composed of two main elements; closed volume and mass flow component. To calculate the dynamics all three conservation equations; Energy, mass and momentum; are used. The HPL calculates the mass and energy balance in the closed volume and the momentum balance in the mass flow component. One of the benefits of using Modelica language is the transparency, that is, behind the sub-components/models are the corresponding equations that describe the dynamics of the model. For example, the reservoir model that represents Fossavatn uses the momentum balance to calculate the mass flow models.

\subsubsection{Pelton Turbine}

The HPL offers two types of turbine models; the Kaplan turbine with guide vanes and runner blades and a basic turbine with guide vane servo which can be used for both Francis and Pelton turbines. The latter turbine model was the preferred choice for Fossárvirkjun.

The turbine model is controlled via a gateActuator input signal from the controller changing the discharge of the turbine. For Pelton turbines this corresponds to the nozzle opening which dictates the flow through the turbine based on a look-up table, i.e.,, TurbineTable. This turbine look-up table contains information about:

- Nozzle Opening [pu]

- Volume Flow Rate $\left[\mathrm{m}^{3} / \mathrm{s}\right]$

- Turbine Efficiency [pu]

Based on the nozzle vane opening, the volume flow rate and turbine efficiency can be calculated. Therefore, the behaviour of how the turbine responds to the control signal depends on the TurbineTable.

The corresponding plot can be seen in Figure 5. The red line represent the turbine efficiency $[\mathrm{pu}]$ and the blue line the volume flow rate $\left[\mathrm{m}^{3} / \mathrm{s}\right]$ corresponding to the gate actuator signal $[\mathrm{pu}]$ on the $\mathrm{x}$-axis.

The Pelton turbine contains two nozzle jets. The first nozzle operates alone under relatively low flow rate $\left(0.124-0.224 \mathrm{~m}^{3} / \mathrm{s}\right)$ until the second nozzle steps in to aid with the increased flow at $0.225 \mathrm{~m}^{3} / \mathrm{s}$. This is clearly visible in Figure 5 where there the blue line becomes suddenly steeper. At this time, the efficiency also increases as the red line displays. bine.

Equation (1) describes the power from the Pelton tur-

$$
\begin{aligned}
P_{\text {turbine }} & =\eta_{\text {hydro }} \cdot \Delta P_{\text {available }} \cdot Q_{\max } \\
& =\eta_{\text {hydro }} \cdot H_{\text {available }} \cdot g \cdot \rho \cdot Q_{\text {max }}
\end{aligned}
$$

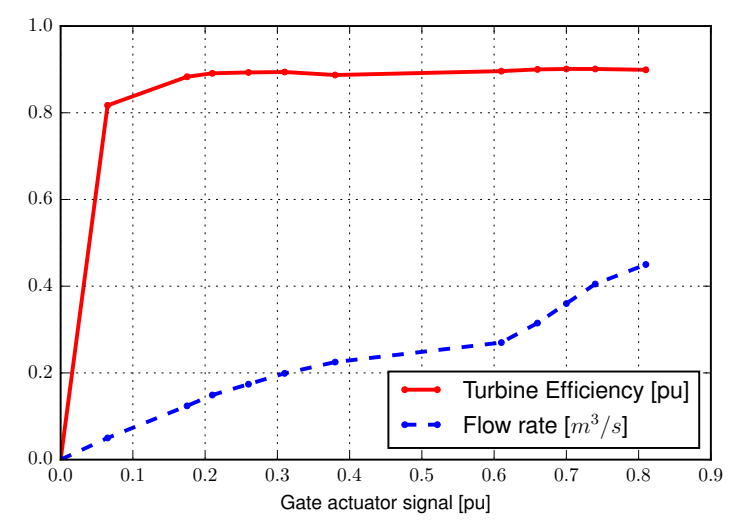

Figure 5. Plot from the TurbineTable

For Fossárvirkjun the maximum power arriving at the turbine shaft is calculated using the maximum efficiency of $91 \%$ (from the TurbineTable):

$$
\begin{aligned}
P_{\text {turbine }_{\max }} & =0.91 \cdot 304 \mathrm{~m} \cdot 9.81 \frac{\mathrm{m}}{\mathrm{s}^{2}} \cdot 1000 \frac{\mathrm{kg}}{\mathrm{m}^{3}} \cdot 0.45 \frac{\mathrm{m}^{3}}{\mathrm{~s}} \\
& \approx 1.221 \mathrm{MW}
\end{aligned}
$$

\subsubsection{Langá}

The Langá component consists simply of a pipe model and a fixed source of temperature and pressure, as can be seen in Figure 6.

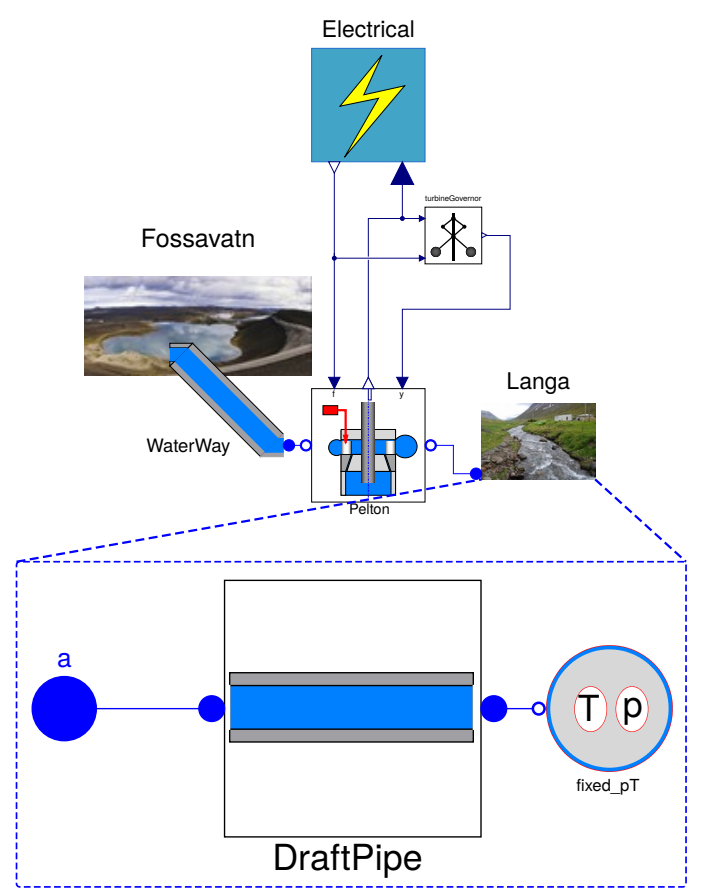

Figure 6. Details of the Langá model

Since the Pelton turbine does not require a draft tube, the pipe that is connected to the output of the turbine is 
only put in there to have the connectors compatible with the fixed source. The fixed source is simply a constant pressure, which is set near to atmospheric pressure.

\subsubsection{Governor}

The governor component is situated above the Pelton turbine as can be seen in Figure 3. The governor is an analogue PID controller where it takes in both the power from the generator and the frequency. The PID controller works under two conditions; No-load and under load. These conditions are set with a Boolean condition; true when noload, false when under load. This Boolean condition allows to run with two sets of parameters, one for speed control and one for power control. The calculations for the error signal into the PID controller is shown here below in Equation (3).

$$
e=\left(f_{0}-f\right)+\left(P_{i n}-P_{r e f}\right)
$$

Since the power system will be run in speed control the governor will have an open MCB breaker, that is the Boolean condition is set to true. The signal will be the speed of the rotor connected to the generator. The governor will therefore control the output by keeping the signal at a speed of $1 \mathrm{pu}$, i.e.,, $50 \mathrm{~Hz}$.

\subsection{Electrical grid}

For the modelling of the electrical grid the Electric Power Library was used. It is a library for electric power systems. The library offers a choice of different phase systems:

- DC system

- AC one-phase system

- AC three-phase abc (non-transformed)

- $\mathrm{AC}$ three-phase dq0 (dq0-transformed)

- AC three-phase dq (dq-transformed) - for a balanced system

The electrical grid was modelled for a balanced system, that is, represented by the AC three-phase dq0 system but omitting the zero-component creating the $\mathrm{AC}$ three-phase dq-transformation. Figure 7 shows the details of the electrical grid component.

The power generated from the Pelton turbine goes as an input to the single mass rotor in per unit which is then connected to the generator through a flange. The synchronous generator generates power with positive direct-quadrature representation. The voltage and reactive power is controlled by the first order control exciter which is connected to the field voltage. In between the load/consumer, is the transformer.

The transformer is a step-up type, from $0.4 \mathrm{kV}$ to $11 \mathrm{kV}$. The $5 \mathrm{~km}$ transmission line then carries the alternating current to the consumer. The consumer is a small fishing village, Súðavík, located on the west coast of Iceland,

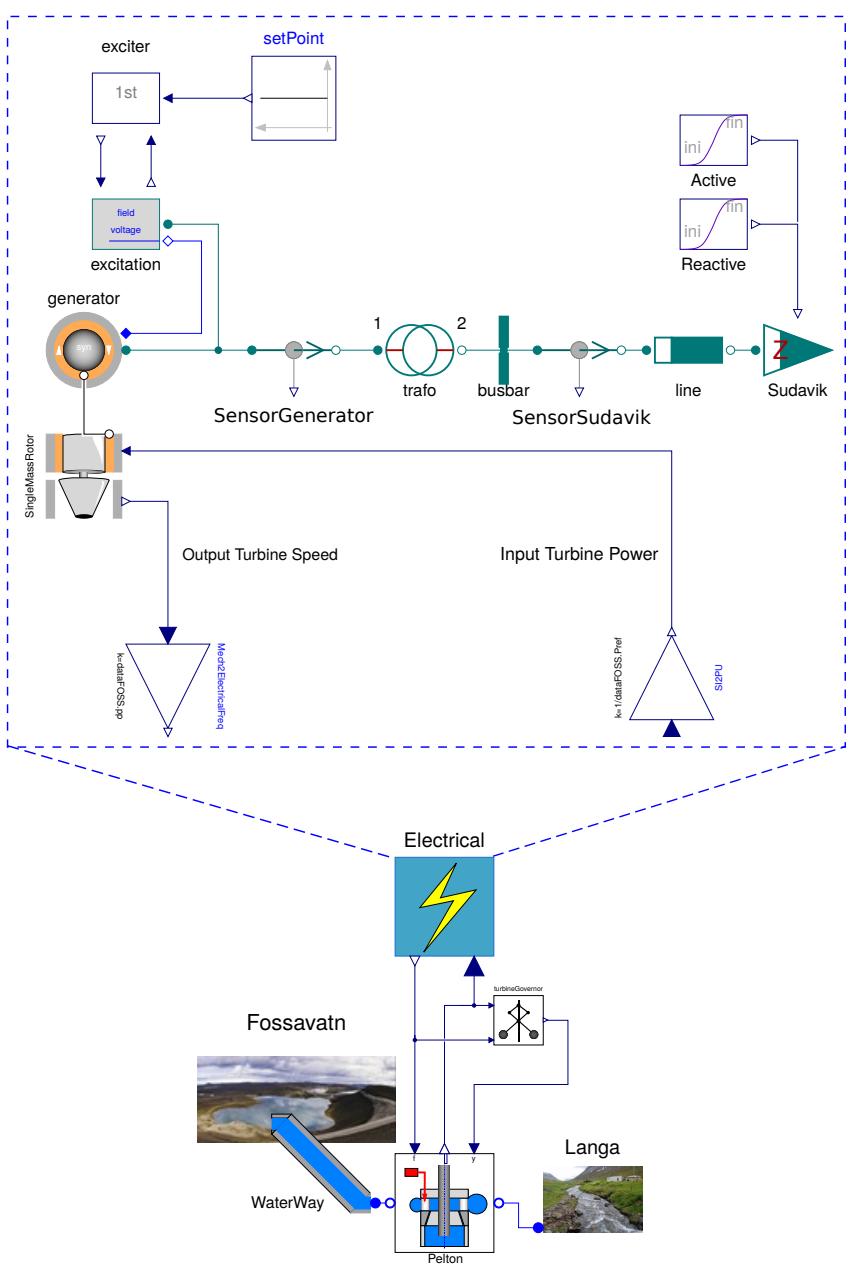

Figure 7. Electrical Component in EPL

$20 \mathrm{~km}$ from Ísafjörður. Half of the power consumed is from households and the other half is consumed by a fish factory.

The EPL is highly complex, where all the components involved are fully mathematically represented. Since EPL is very detailed, the amount of input parameters required by the user is plentiful. This can be beneficial for accuracy reasons but does invite parameterisation error. There are a great number of input parameters that have to be known and correspond to a real scenario power system. Compared to the HPL, EPL is very sensitive to parameter inconsistencies.

The main components involved are:

\subsubsection{Single Mass Rotor}

Represents one single stiff rotating mass, defined with inertia constant $\mathrm{H}$ [s]. The single mass rotor is used as a connector between the generator and the Pelton turbine. A power signal from the HPL turbine model is used to calculate the rotational speed based on the load that the connected generator represents. 


\subsubsection{Synchronous Generator}

This component is a three-phase-balanced-dq, AC synchronous machine with electric excitation. The user can choose from a Y or Delta topology.

\subsubsection{Exciter}

The exciter controls the excitation DC voltage with first order control which is directly determined by the per unit voltage control signal. The exciter controls both the reactive power and the voltage in the field.

\subsubsection{Transformer}

Ideal three-phase-balanced-dq step-up transformer. The magnetic coupling is ideal with no stray-impedance and zero magnetisation current. The user then chooses between $\mathrm{Y}$ and Delta topology at primary and secondary side. On the primary side there is the $0.4 \mathrm{kV}$ from the generator and on the secondary side the resulting $11 \mathrm{kV}$ from the transformer.

\subsubsection{Súðavík Load}

Inductive three-phase-balanced-dq load. Consumes active and reactive power of nominal voltage. Power is derived from the apparent power multiplied with the power factor input.

\section{Simulation}

The act of simulation is the experiment done on the model. The simulation results depend highly on how well the model represents the real system. One should always note that the simulation is only valid under the limitation and conditions given and can never represent the system completely, but is mainly an approximation for understanding the system. The simulation is only valid for the given input data (Tiller 2016). There were two types of simulation scenarios of interest.

\section{- $20 \%$ load rejection}

- The water hammer effect

Since the power system is in an island operation it is important to monitor the behaviour of any disturbances in the system. The load rejection simulation was constructed by a $20 \%$ sudden load rejection. This scenario is trying to imitate the incidence when there is a power shut-down, e.g., a shut-down of a large factory. The water hammer effect is particularly of interest for two reasons: There have been incidents where the pressure on the bottom of the pressure shaft raised above the pressure threshold of the pipe's material, resulting in an outburst. Second reason is the lack of surge tank in the power system. The objective of the surge tank is to absorb the pressure and therefore take care of the sudden pressure rise in the pressure shaft, like has been stated. Omitting the surge tank leads to an increase in the travel distance of the impact waves in the conduit which causes increase in inertia of the water mass (Kiselev 1974).

\subsection{Load Rejection}

The load rejection simulation was constructed in a way that the induction load modelled was changed from its original steady active power load of $1.239 \mathrm{MW}$ to a sudden drop of $20 \%$ resulting in an active power of $0.996 \mathrm{MW}$. Figure 8 illustrates the model basis for the simulation consisting of the water-way, governor and electrical part.

The results from the simulation can be seen in Figure 9 where the plot illustrates the expected changes in active power, reactive power and the flow into the turbine. The aim here was to keep the rotor speed (frequency) consistent at 1 per unit $(50 \mathrm{~Hz})$. The upper plot shows the rotors speed [pu] as the red line and the flow $\mathrm{m}^{3} / \mathrm{s}$ in to the turbine as the blue line. The control action taken is to decrease the nozzle opening to compensate for the power loss caused by the load rejection. Similarly, the active and reactive power $[\mathrm{W}]$ decreased accordingly.

Similarly, it is interesting to see if the voltage stays constant since the aim of the exciter (voltage regulator) is to keep the voltage steady. On the upper plot in Figure 10 the results from the $20 \%$ Load Change illustrate the effect it has on the voltage both on the low voltage side and the high voltage side, that is, before and after the transformer. On the lower plot in the same Figure 10 the pressure at inlet of the turbine rises from 27.47 bar to 29.19 bar, thus the pressure increase is $1.72 \mathrm{bar}$. This increase in pressure is a result of the output of the controller, closing the valve to reduce the flow.

To summarise, Table 2 reflects the numerical results from the $20 \%$ load rejection.

Table 2. $20 \%$ load rejection

\begin{tabular}{lccc}
\hline & Original & Change & Difference [\%] \\
\hline Active P. [MW] & 1.239 & 0.996 & -19.61 \\
Reactive P. [Mvar] & 0.138 & 0.111 & -19.56 \\
Pressure [bar] & 27.47 & 29.19 & 5.89 \\
Flow [m ${ }^{3} / \mathrm{s}$ ] & 0.454 & 0.341 & -24.89 \\
\hline
\end{tabular}

Since the objective of the controller is to keep the rotor speed constant, three different load rejections were implemented to see the reaction of the rotor. Figure 11 shows the results after the following load rejections; $20 \%, 40 \%$, $60 \%$ and $80 \%$. The desired outcome is to keep the speed at $1 p u(50 \mathrm{~Hz})$ after each load-rejection.

As can be seen in Figure 11 it follows that higher the load rejection the more amplitude the oscillations have at the instance when the load changes.

\subsection{The Water Hammer Effect}

The following simulations were done in order to investigate pressure rise in the pressure shaft and the effect it has on the governing stability due to the oscillations in the pressure shaft. A rapid change in the flow can lead to major oscillations in the water-way, also called the water hammer effect. Figure 12 shows the model constructed 


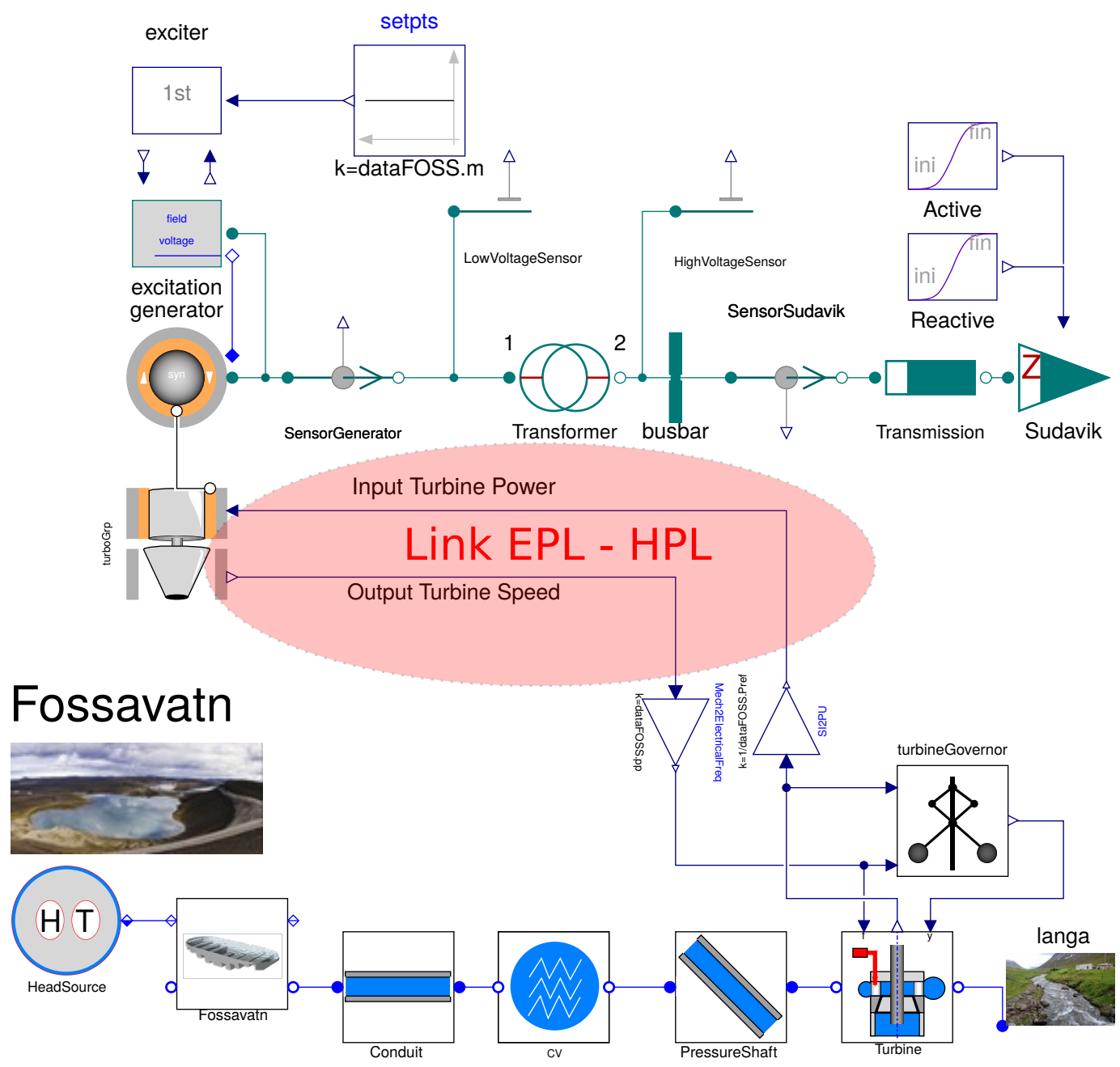

Figure 8. Hydropower model of the load changes
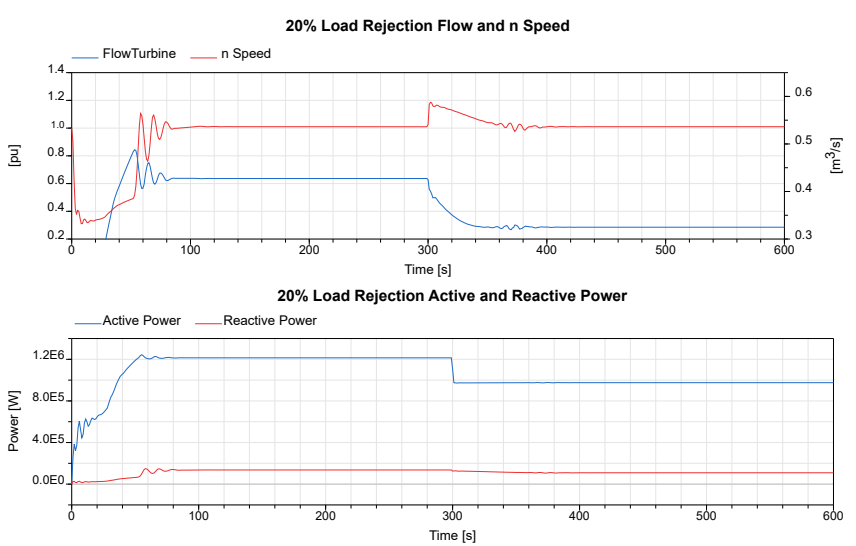

Figure 9. Simulation results of $20 \%$ load changes

for the simulation analysis. It is worth noting that there are two water-way models. One is connected to the electric part, controlled by the load and the governor. The second water-way is situated below is a stand-alone without a turbine, controller or an electrical part. This is modelled
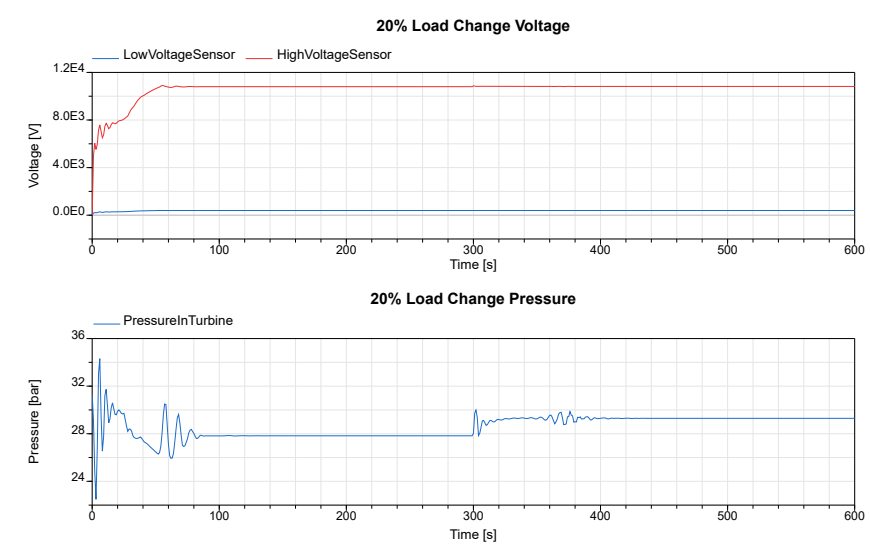

Figure 10. 20\% load changes, voltage and pressure

this way to isolate the water hammer effect to see whether there is a difference between the complete power system model and the isolation of the water-way. On the standalone water-way, a valve is installed instead of the turbine, the flow through the valve is imitated after the turbine. 


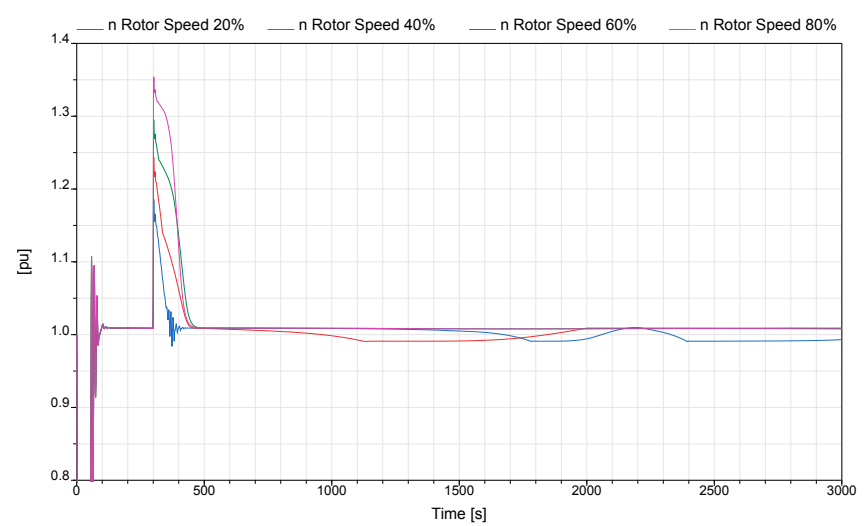

Figure 11. Rotor speed after various load rejections

The reason for the creating a stand-alone water-way is simply to allow more direct flow changes and investigations without a controller modifying the control signals because of some safe-guard and control delay restrictions that might be present/activated.

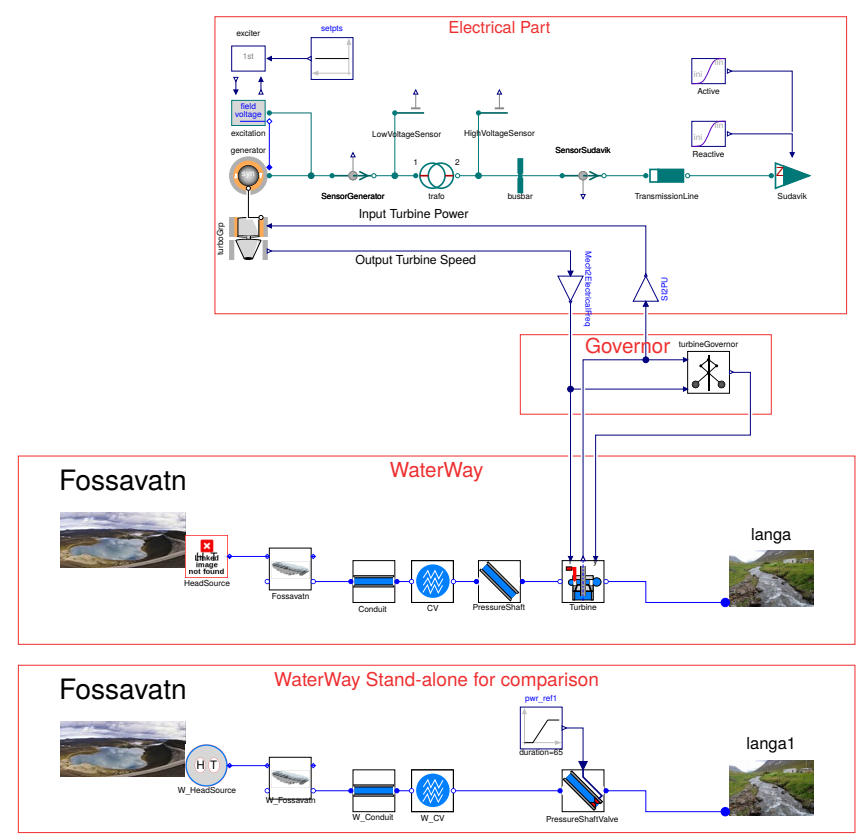

Figure 12. Overview of the model used for the water hammer effect scenario

It follows that in order to compare these models, the control signal from the governor in the upper model has to be the same as the valve/nozzle closing time. The control signal to the valve in the stand-alone model is a simple ramp function. The resulting plot can be seen in Figure 13. Since the control system is involved in the complete model, it is not possible to simply close the nozzle in the Pelton turbine. To achieve a fully closed turbine the load has to be shut-down first. Therefore, the load is set to zero at time 250 seconds, from its original load. The time it takes to fully close the turbine until there is no flow through, is 65 seconds.
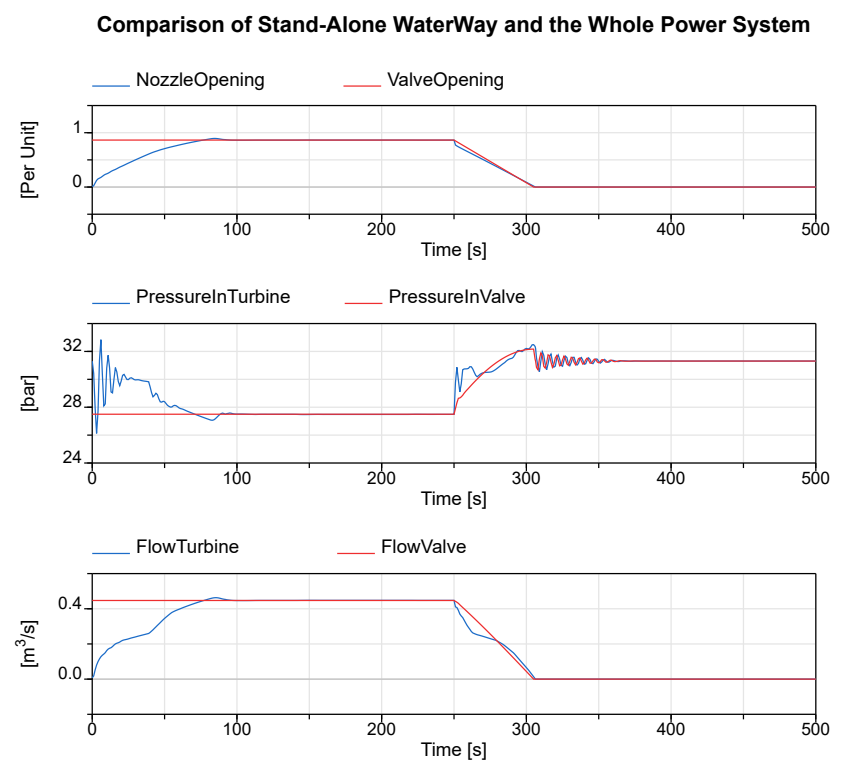

Figure 13. Water hammer plot comparing both models

The top plot shows the nozzle closing signal from the governor and the equivalent ramp signal to close the valve. As can be seen in Figure 13 they are almost identical. The most important is that their closing time is the same, which it is.

The comparison between the pressure drop in the turbine and valve can be seen on the middle plot. As expected, for the whole power system there is fluctuation in the pressure at the beginning since the governor is reacting to the full load. However, for the stand-alone water-way the valve starts fully opened. Eventually after 100 seconds the pressure in the turbine settles to the same pressure as the valve. At the 250 seconds the turbine and valve close. Apart from the pressure oscillation in the whole system, the models respond in a similar dynamic behaviour. Similarly, on the bottom plot the flow out from the turbine and the valve behave in a similar manner.

Since the comparison between the stand-alone waterway and the whole system gave identical results the standalone water-way can undergo further analysis. It was important to confirm that for the same opening degree, pressure and flow the results are identical before and after closing. For worst-case scenario in terms of the water hammer effect is if the load in Súðavík completely shuts-down. This can be seen in the resulting plot on Figure 13. There the time it takes to close the turbine is 65 seconds.

Having now an identical water-way with a simple pressure shaft with valve, an analysis of a faster closing of the valve can take place to test the minimum closing time to see the maximum allowable pressure in the pressure shaft.

Stated in the technical data from the manufacturer the allowable pressure rise in the pressure shaft is $15 \%$. We 
investigated how quickly the valve can close. This was done by gradually decreasing the closing time starting from at 56 seconds as shown in Figure 13 and then inspecting the pressure rise for smaller closing times. Table 3 displays the peak/maximum pressure rises for a series of faster closing times.

Table 3. Closing time in water-way analysis

\begin{tabular}{crr}
\hline Closing time & \multicolumn{2}{c}{ Pressure } \\
[s] & Max [bar] & Rise [\%] \\
\hline 56 & 32.26 & 0.8 \\
40 & 32.58 & 1.8 \\
15 & 34.76 & 8.6 \\
12 & 35.59 & 11.2 \\
10 & 36.71 & 14.7 \\
\hline
\end{tabular}

The corresponding plots can be seen in Figure 14. The upper plot shows the closing signal to the valve and the bottom plot shows the pressure oscillations at the inlet of the valve. The most aggressive pressure rise is between closing time (10-15 seconds), resulting in heavy oscillating dynamic of the water wave.
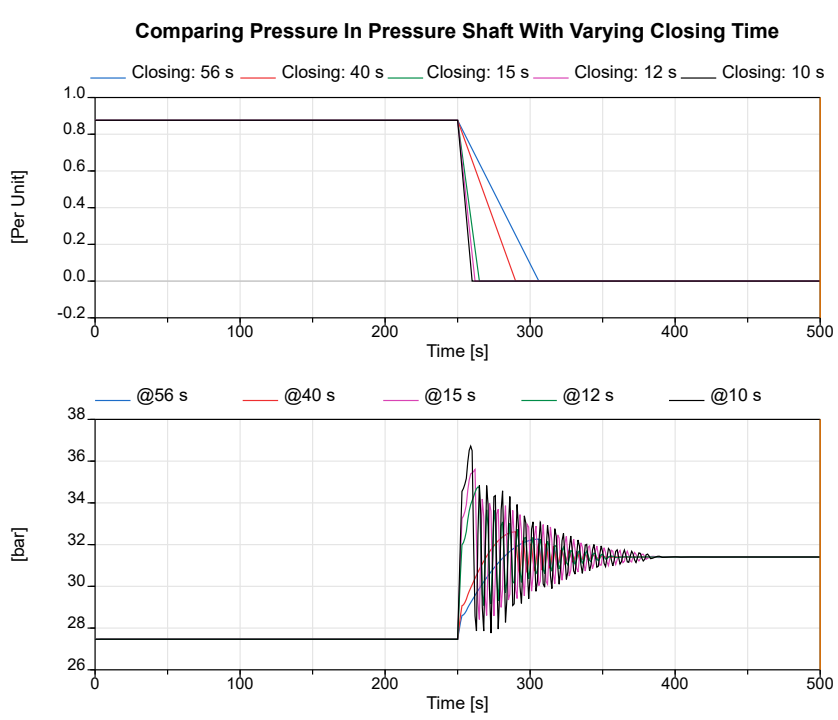

Figure 14. Closing time analysis on stand-alone water-way

Figure 15 shows a schematic of the water-way where the blue line represents the actual pipe alignment and the red/yellow lines represent the pipe as modelled in Modelica split up by segments. Each pipe is divided into four segments of equal length. One could increase the resolution by using more segments but in this case the default of four was sufficient. Both the elevation of the pipe segments and corresponding pressure is marked on the schematic. The pressure build-up due to the closing of the valve from the intake at $343 \mathrm{~m}$ and down to the turbine inlet can be seen in Figure 16.

\section{Conclusion}

\subsection{Load Rejection}

The load rejection was carried out while monitoring the flow into the turbine, speed of the rotor, pressure, voltage and power. The variables of interest gave a promising outcome indicating in a dynamic model that should represent Fossárvirkjun power plant adequately. Since having information regarding $20 \%$ load change from the manufacturer, similar load change scenario was implemented in order to validate the results.

As for the change in active and reactive power due to the load change, both decreased immediately around $19.6 \%$ in power. They are controlled by separate controllers, active power by the PID governor and the reactive by the voltage regulator, therefore a good indicator that both controllers are taking similar action. When looking into whether the results are as expected is to

Also the in (1) calculated theoretically available Pelton turbine power of $1.221 \mathrm{MW}$ compares well with the simulated active power of $1.239 \mathrm{MW}$.

The same can be said for the voltage in Figure 10 . The objective of the voltage regulator is to keep the voltage constant during load rejections. The voltage on both, the low voltage side and the high voltage side, remains constant throughout the disturbance which results in a good performance from the voltage regulator.

\subsection{The Water Hammer effect}

The analysis of the water hammer effect was implemented in Section 3.2 where the stand-alone water-way was compared to the whole power system. The results in Figure 13 were promising as both models yielded to similar behaviour. Since both water-ways are identical, apart from the valve in the pressure shaft on the stand-alone unit, it was expected that the pressure would be the same. The pressure and the flow in the turbine are of course more oscillating since being represented by the whole power system and thus controlled by the governor while the standalone model shows a more ideal behaviour.

After having the above results confirm that the standalone unit had identical result to the whole power system. More aggressive worst-case scenario shut-down of the valve took place. Closing time analysis was therefore implemented while observing the pressure in the pressure shaft of the stand-alone unit. Figure 14 showed the pressure increases with different closing times. To no surprise, the pressure increased as expected from the original closing time of the valve of 56 seconds down to 10 seconds.

The worst-case scenario shut-down of the valve indicated that a closing time of 10 seconds creates a maximum pressure increase to $36.71 \mathrm{bar}$. This is something that is dangerously near the maximum allowed pressure of $32 \mathrm{bar}+15 \%$, see Table 1 . Therefore, the results indicate that the valve/turbine should not be closed/shutdown in under 12 seconds. 


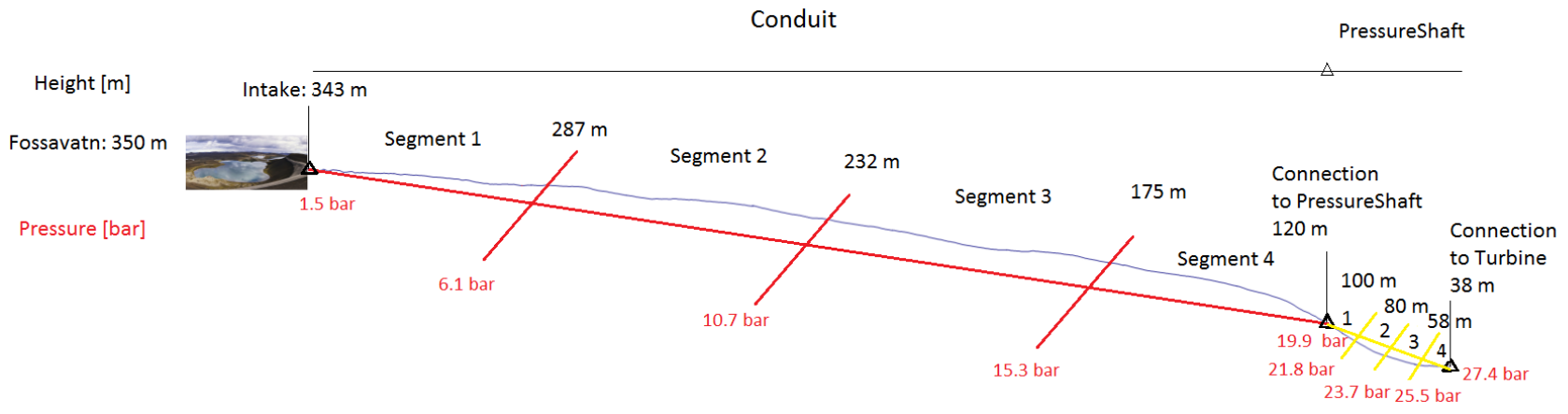

Figure 15. Pipe segments Fossavatn to turbine/valve inlet

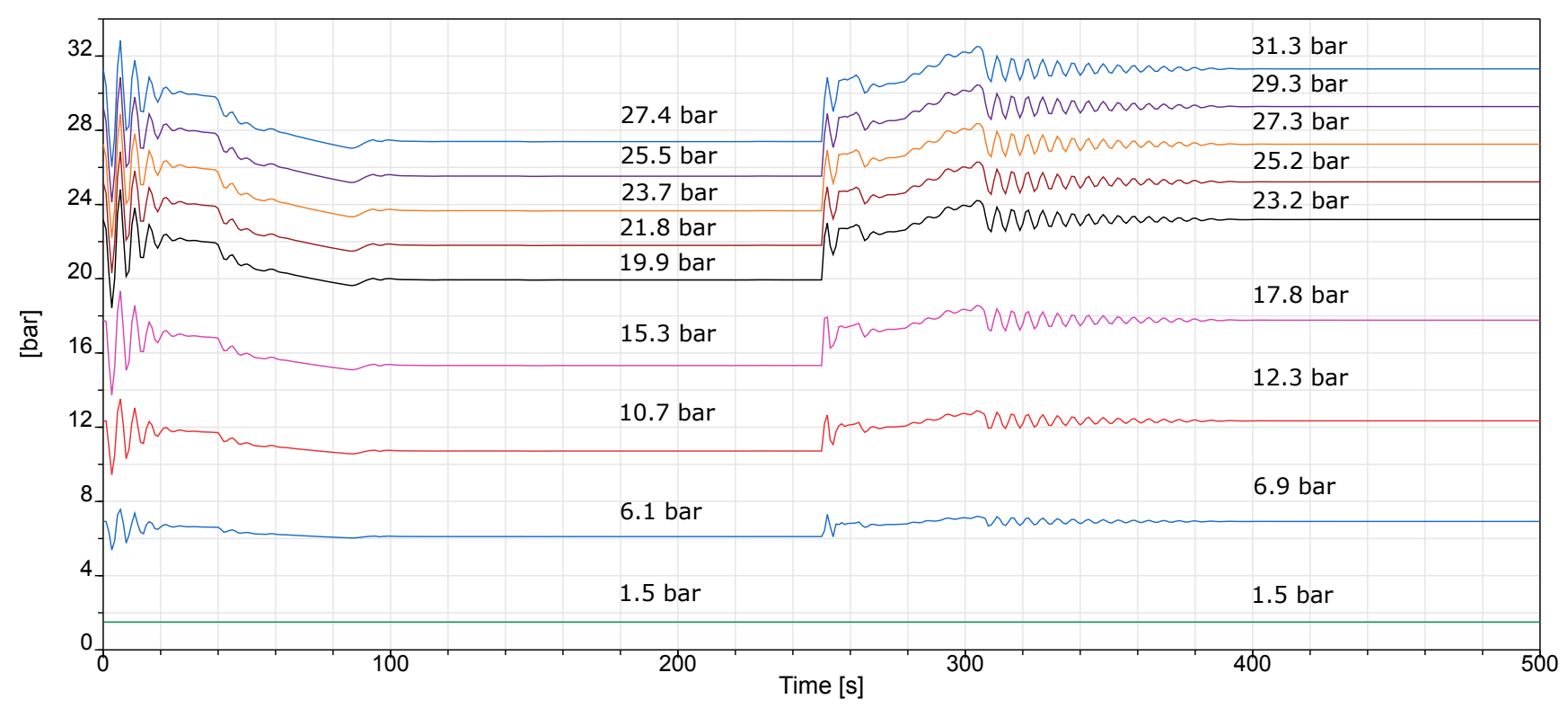

Figure 16. Pressure build-up in pipe segments from segment 1 (bottom) through to turbine connection (top)

\section{References}

Dassault Systèmes (2016). Dymola. Modelon. URL: http : / / www . dymola . com (visited on 05/28/2016).

Elmqvist, Hilding, Hubertus Tummescheit, and Martin Otter (2003). "Object-oriented modeling of thermofluid systems". In: pp. 269-286. URL: http : / / elib.dlr.de/11988/ (visited on 05/30/2016).

International Hydropower Association (2016). A brief history of hydropower. International Hydropower Association. URL: http: / / www . hydropower . org / abrief - history - of - hydropower (visited on 05/28/2016).

Kiselev, G. S. (1974). "Effect of water inertia in penstocks on regulating characteristics of hydraulic units". In: Hydrotechnical Construction 8.4, pp. 337-341. ISSN: 1570-1468. DOI: 10 . 1007 / BF 02406941 . URL: http://dx.doi.org/10.1007/BF02406941.
Modelon AB (2016). Modelon Libraries. Modelon. URL: http : / / www . modelon . com / products / modelica-libraries / (visited on 05/28/2016).

Munoz-Hernandez, German Ardul, Sa'ad Petrous Mansoor, and D. I Jones (2013). Modelling and controlling hydropower plants. London; New York: Springer. ISBN: 978-1-4471-2291-3. URL: http: / / public . eblib . com / choice / publicfullrecord . aspx?p=973672 (visited on 05/25/2016).

Refurbishment of the Fossár hydro Power Plant (2015). Verkís. URL: http : / / www . verkis . com / about - us / news / refurbishment - of the-fossarvirkjun-power-plant (visited on 05/28/2016).

Tiller, Michael M. (2016). Modelica By Example. Ed. by Michael M. Tiller. URL: http : / / book . xogeny • com/ (visited on 01/20/2017). 